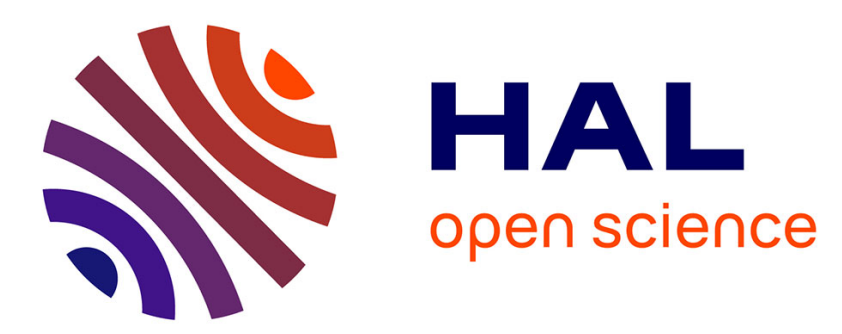

\title{
A Field Study of Momentary Liquefaction Caused by Waves around a Coastal Structure
}

Mathieu Mory, Hervé Michallet, D. Bonjean, I. Piedra-Cueva, Jean-Marc

Barnoud, Pierre Foray, Stéphane Abadie, P. Breul

\section{To cite this version:}

Mathieu Mory, Hervé Michallet, D. Bonjean, I. Piedra-Cueva, Jean-Marc Barnoud, et al.. A Field Study of Momentary Liquefaction Caused by Waves around a Coastal Structure. Bulletin of the American Meteorological Society, 2007, 133 (1), pp.28-38. 10.1061/(ASCE)0733-950X(2007)133:1(28) . hal-00267299

\section{HAL Id: hal-00267299 \\ https://hal.science/hal-00267299}

Submitted on 18 Dec 2018

HAL is a multi-disciplinary open access archive for the deposit and dissemination of scientific research documents, whether they are published or not. The documents may come from teaching and research institutions in France or abroad, or from public or private research centers.
L'archive ouverte pluridisciplinaire HAL, est destinée au dépôt et à la diffusion de documents scientifiques de niveau recherche, publiés ou non, émanant des établissements d'enseignement et de recherche français ou étrangers, des laboratoires publics ou privés. 


\title{
A Field Study of Momentary Liquefaction Caused by Waves around a Coastal Structure
}

\author{
M. Mory'; H. Michallet²; D. Bonjean ${ }^{3}$; I. Piedra-Cueva ${ }^{4}$; J. M. Barnoud ${ }^{5}$; P. Foray ${ }^{6}$; S. Abadie ; and \\ P. Breul ${ }^{8}$
}

\begin{abstract}
This paper presents the results of field experiments carried out around a bunker from the Second World War situated on the beach. The structure was surrounded by water at high tide and subject to intense wave forcing. By positioning pressure sensors at different levels inside the soil, simultaneous time series of pore pressure measurements were acquired. They demonstrated that the sediment layer on top of the bed does not remain continuously in static equilibrium. Momentary liquefaction was observed as the occurrence of an upward pressure gradient, which could overcome the effective weight of the sediment layer. Using a Fourier analysis, a comparison was made with the theory put forward by Sakai et al. in 1992 whereby the damping of pore pressure variations inside the soil can be quantified. This indicated the existence of a significant amount of gas inside the soil, which was confirmed in the field by geoendoscopic videos.
\end{abstract}

Keywords: Coastal structures; Liquefaction; In situ tests; Measurement; Field tests; Scour.

\section{Introduction}

The occurrence of momentary liquefaction of a sandy bed by water waves passing over the soil has been described theoretically by various authors. Mei and Foda (1981) proposed a theory of the phenomenon and Sakai et al. (1992) derived from this theory a set of equations that describes the variation in time and space of the effective stresses produced inside a sandy bed when water gravity waves pass over it. The pore pressure variations produced at different depths inside the bed are dampened with increasing depth and are subject to a phase shift as compared with variations at the bed surface. The two effects may lead to the occurrence of momentary liquefaction. In real flow and soil conditions the occurrence of momentary liquefaction is highly sensitive to the

\footnotetext{
${ }^{1}$ Professor, ENSGTI (Univ. de Pau et des Pays de l'Adour), BP 7511, 64075 Pau Cédex, France.

${ }^{2}$ Research Associate, LEGI (UJF-INPG-CNRS), BP53, 38041 Grenoble Cédex 9, France.

${ }^{3} \mathrm{Ph} . \mathrm{D}$. Student, Laboratoire 3S (UJF-INPG-CNRS), BP53, 38041 Grenoble Cédex 9, France.

${ }^{4}$ Professor, ENSGTI (Univ. de Pau et des Pays de l'Adour), BP 7511, 64075 Pau Cédex, France; on leave from Univ. de la Republica, Montevideo, Uruguay.

${ }^{5}$ Technician, LEGI (UJF-INPG-CNRS), BP53, 38041 Grenoble Cédex 9, France.

${ }^{6}$ Professor, Laboratoire $3 S$ (UJF-INPG-CNRS), BP53, 38041 Grenoble Cédex 9, France.

${ }^{7}$ Associate Professor, LaSAGeC (Univ. de Pau et des Pays de l'Adour), Allée du parc Montaury, 64600 Anglet, France.

${ }^{8}$ Associate Professor, LERMES-CUST, rue des Meuniers, BP 206, 63174 Aubière Cédex, France.
}

presence of gas inside the soil, as shown by a parametric study of the equations of Sakai et al. (Gratiot and Mory 2000).

To our knowledge the occurrence of momentary liquefaction produced by surface waves has not been observed in the field. We are aware of different experiments in the framework of coastal engineering or of mine burial studies but they were not conclusive with respect to the observation of liquefaction. This paper reports on a field experiment which was carried out during the LIMAS project. It aimed at observing liquefaction and scour around a coastal structure in the field. Following the conclusions of the parametric study by Gratiot and Mory (2000) a site for the field experiment was chosen at Capbreton on the Atlantic coast in southwest France. This coast is subject to very strong wave forcing. A bunker from the Second World War which is now situated on the beach (due to the significant beach retreat observed there) was used as a coastal structure as it appeared to be a suitable object for this experimentation. Due to its weight and size, the bunker is representative of coastal engineering structures. It is also very stable throughout the duration of experiments, and measurement instruments could be fixed to it without causing damage. The bunker is fully emerged at low tide and partially submerged at high tide (when the water is $2 \mathrm{~m}$ deep). These conditions offer a reasonable opportunity of obtaining different levels of gas content inside the soil during a tidal cycle.

The experiments were carried out during high tide periods. The bunker was instrumented at two locations (in the middle of the wall facing the ocean and at the corner) with different systems: pore pressure sensors at different depths inside the bed, bed level monitoring, flow velocities, and wave height measurements in the vicinity of the bunker. Gas content measurements inside the bed were also carried out using two systems. A geoendoscope video provided visualizations of air content inside the soil, and a sampling technique developed by Sandven and Long (2004) in the course of the LIMAS project was also used. Field data were additionally acquired on changes in the beach morphodynamics and on geotechnical soil properties. The experiments were performed jointly by specialists in soil mechanics and geotechnics, 


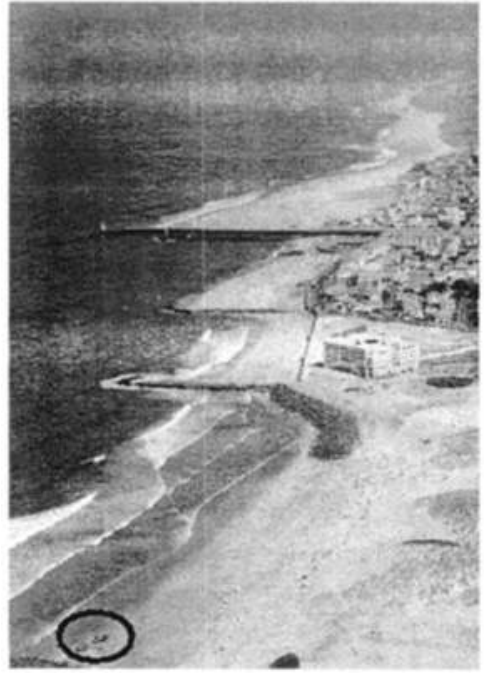

Fig. 1. General view of the Capbreton site (courtesy of C. Carrère)

surface wave dynamics and sediment transport, instrumentation, and geoendoscopy.

The following is divided into five parts. The second section presents the experimentation site, general observations of beach sediment changes and geotechnical soil properties. The specific measurement techniques used in the course of the study to measure pore pressure inside the soil, monitor bed level changes, measure flow properties, and estimate gas content are described in the next section. The following section reports on the experimentation procedure. The fifth section presents the main results of the field experiment, in particular the observations and analysis of liquefaction events and statistics of liquefaction occurrence during a tidal cycle. The final section is a general conclusion. Due to limited space in this paper, only a selection of the main results of the study will be presented. As a technical paper in a special issue devoted to the LIMAS project, the purpose here is to give a general account of the study, including both the results and a description of the environment.

\section{The Field Experiment}

\section{Description of the Site}

The field experiment was carried out at Capbreton, $30 \mathrm{~km}$ north of Biarritz on the Atlantic coast of Aquitaine, in southwest France. The sandy coast of Aquitaine is subject to strong wave activity, producing a significant mean longshore drift toward the south. The averaged movement of the Aquitaine coast is, in general, characterized by a significant retreat of the beach (see Howa et al. 1999). Fig. 1 shows a photograph of Capbreton beaches. The field experiment was carried out in the southern part of the Capbreton beaches. Because the beach retreat has been there about $100 \mathrm{~m}$ over the past 30 years, a group of 9 bunkers (whose location is indicated in the circle in Fig. 1) is now in the surf zone. The typical horizontal scale of the bunkers ranges from 10 to $20 \mathrm{~m}$ and the typical distance between two neighboring bunkers is about $50 \mathrm{~m}$. Investigations were only carried out around nontilted bunkers, i.e., those which can be considered as approximately vertical cylindrical structures. The field experiments were carried out during periods of high tide conditions, when the bunkers are partially submerged at full tide and subjected to wave

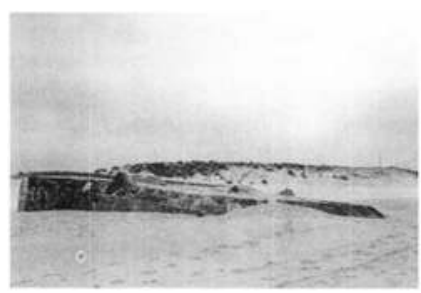

(a)

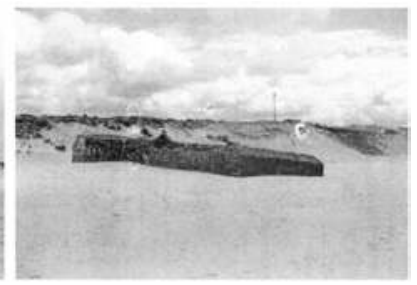

(b)
Fig. 2. Central bunker taken on (a) April 25, 2002; (b) April 29, 2002

action. Various wave conditions were obtained ranging from calm to very rough waves. Major morphodynamic beach changes were observed; some bunkers that were seen to be almost completely buried during certain periods became almost fully emerged after a few days. Fig. 2 compares the level of sediment around the same bunker measured four days apart. The sediment erosion in front of the bunker was measured and found to be about $1.5 \mathrm{~m}$ in 4 days. Three field experiment trials were carried out around this bunker, referred to the "central" bunker, in Fall 2002, Spring 2003, and Fall 2003. During these periods the emerged height of the structure was over $2.5 \mathrm{~m}$. Investigations were carried out in the vicinity of another bunker (referred to as the "offshore" bunker) in Spring 2002 because the central bunker was almost buried at the beginning of this trial.

\section{Measurements of the Bunker Position and Morphodynamic Beach Changes}

Because the bunkers have been obviously displaced between 1968 and 2003; and because very significant morphodynamic changes were observed in the beach during the two years of our investigations, measurements of the displacements of marked points at the four corners on top of the bunker (see Fig. 3) were made using a differential global positioning system (DGPS) (Thales Scorpio $6502 \mathrm{MK}$ ). The RMS statistical errors on the measurement of the position of a fixed point identified on the sea wall at Capbreton were found to be 4.4 and $4.0 \mathrm{~cm}$ in the horizontal and vertical directions, respectively. The measured variations in

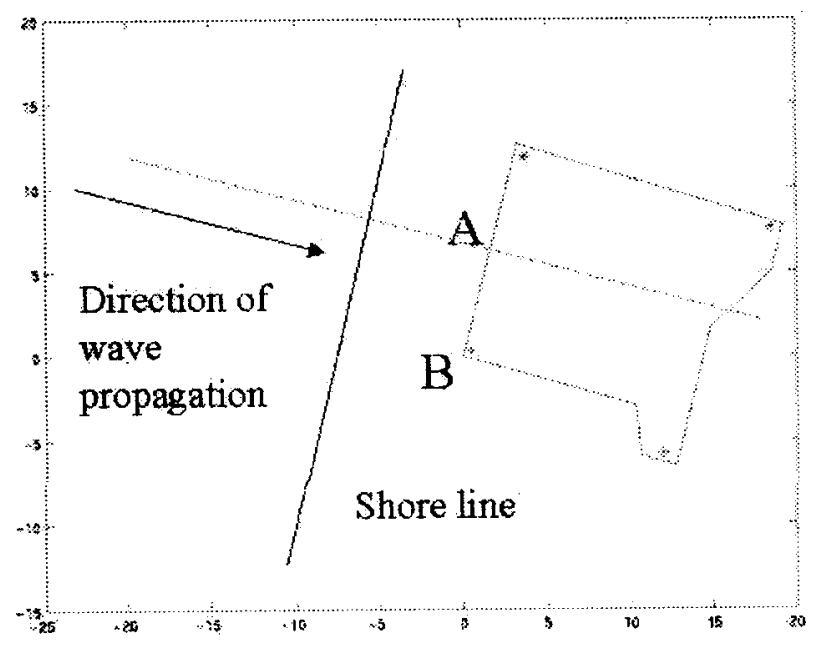

Fig. 3. Diagram of the central bunker in the horizontal plane. Stars indicate the points on the bunker monitored using the DGPS; A and B indicate the two positions investigated in front of the bunker. 


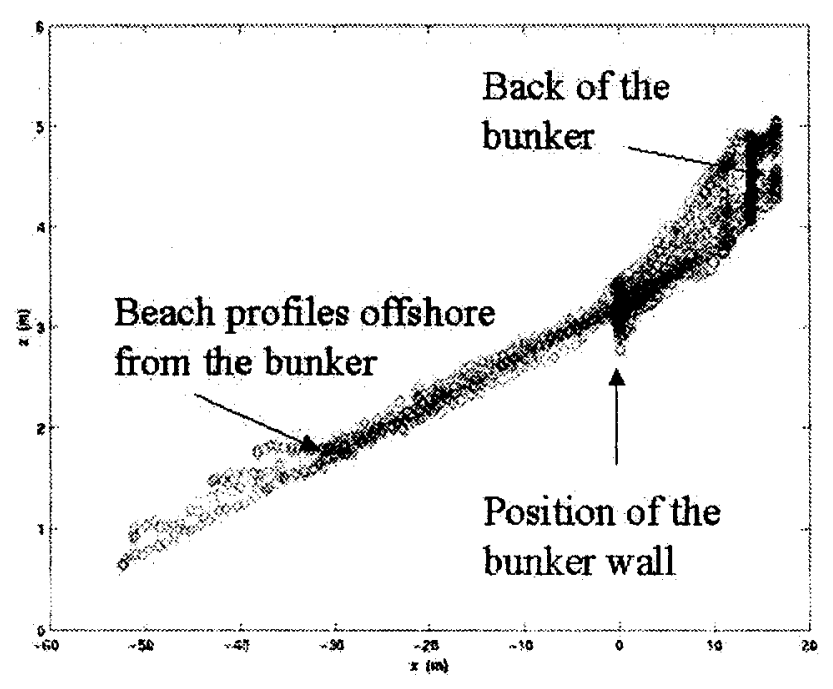

Fig. 4. DGPS beach morphodynamic data measured from September 24 to October 2, 2003 (data are projected along the dashed line in Fig. 3)

the positions of the bunker corners were found to be within this degree of uncertainty and it was therefore concluded that the position of the bunker did not change between April 2002 and September 2003.

The DGPS was additionally employed during field trials to measure morphodynamic changes in the beach in the vicinity of the investigated bunker. At each low tide the bed level was measured around the bunker and a beach profile was taken along a line perpendicular to the bunker wall facing the ocean. Fig. 3 shows a diagram of the bunker in the horizontal plane. The paths along which the soil level was measured are the perimeter around the bunker and the profile offshore from the bunker starting from the bunker wall. Fig. 4 summarizes the beach changes measured during the final field trial. For the sake of simplicity, all the measurements are projected along the beach line indicated by the dashed line in Fig. 3. The data sets superimposed in Fig. 4 were measured at different low tides over the 9 days of the field trial. It can be seen that the measured beach profile offshore from the bunker was barely modified. Significant sand accretion is also clearly visible at the back of the bunker, where it reaches an order of magnitude of about $1 \mathrm{~m}$. Sand is brought inshore during the high tide conditions. The data presented are not the most striking ones because wave conditions were calm during the final field trial. This is obviously very different from the observations made in April 2002 (Fig. 2), during which DGPS data could not be acquired systematically. Because most of the results presented in this paper were measured during the final trial, DGPS data corresponding to the same period are presented in Fig. 4 in order to present a complete data set for discussion.

\section{Sediment and Soil Geotechnical Properties}

Visually, the sand on the beach is homogeneous. The mean sediment size is $d_{50}=350 \mu \mathrm{m}$. The sediment size distribution of a sand sample taken in the vicinity of the bunker shows that most of the sand is contained in a narrow band $\left(d_{10}=220 \mu \mathrm{m}\right.$ and $\left.d_{90}=500 \mu \mathrm{m}\right)$. The sand distribution did not appear to vary significantly in time. The intermittent deposition of limited quantities of gravel of a few millimeters in size on the sandy bed was sometimes noticed.
The disturbance produced when setting the measurement devices around the bunker made the soil looser than undisturbed soil. At each low tide, penetrometer tests were carried out at different locations in the vicinity of the central bunker using a dynamic penetrometer (PANDA). These measurements aimed at estimating how rapidly the soil properties were recovered after a disturbance, and at determining the spatial variability in geotechnical properties in the vicinity of the bunker. The results of the penetration tests are only summarized in the following (see Bonjean et al. 2004, for details). A typical vertical profile of the dynamic peak resistance $Q_{d}$ (which is related to the soil density for a given particle size distribution), measured in undisturbed soil, displays a gradual increase in the peak resistance in the first tens of centimeters of penetration. The average resistance value at about $1 \mathrm{~m}$ depth is in the range $2-5 \mathrm{MPa}$. For the conditions of the final field trial, Bonjean et al. (2004) estimated that a duration of two tides is sufficient to retrieve a state of compaction similar to that observed in undisturbed soil. Vertical profiles of the dynamic peak resistance exhibiting a different structure were measured during the field trial in April 2003, when rough wave conditions occurred and significant bed level variations were observed. The general trend of sediment transport during this field trial involved severe erosion about $1 \mathrm{~m}$ deep in front of the bunker and significant deposition at the back. A loose sand layer on top of the soil was observed in front of the bunker. Its was about $50 \mathrm{~cm}$ thick in the middle of the front side of the bunker and about $1.5 \mathrm{~m}$ close to the corner. The further the measurement was made from the bunker, the thinner the loose sand layer was. Bonjean et al. (2004) attributed the existence of this loose sand layer to the significant scour and burial produced during each tidal period by the action of high waves. The phenomenon was observed to a more limited extent in the calmer conditions of the final field trial.

\section{Measurement Techniques for Observing Scour and Liquefaction}

\section{Pore Pressure Measurements in the Soil}

The pressure in the water layer and inside the soil was measured by five pressure sensors installed in a vertical aluminum bar fixed on the bunker. Druck PDCR 4030 pressure sensors were used. They allow the measurement of a relative pressure up to $7 \times 10^{4} \mathrm{~Pa}$ with a precision of $0.08 \%$. This corresponds to an accuracy in water depth of about $0.5 \mathrm{~mm}$. The transducers were fixed every $30 \mathrm{~cm}$ along the bar. A diagram with dimensions is shown in Fig. 5. Each pore pressure sensor is placed inside a cavity of volume approximately equal to $5,000 \mathrm{~mm}^{3}$ in which the pressure is adjusted to the soil pressure through a porous stone. The porous stone flushes with the bar surface facing the ocean. Its surface, which is actually the sensing element of the system measuring the pore pressure, is approximately equal to $20 \mathrm{~mm}^{2}$. Special attention was paid during installation to fill with water the inner volume, so that the cavity does not change the time of response of the pressure transducer. The bar itself was firmly linked to the bunker by means of several rawlplugs deeply inserted in the concrete, making any relative movement between the bar and the bunker impossible. The bar was positioned at low tide by excavating a large volume of sand until the water level was reached. The bar was then pushed about $50 \mathrm{~cm}$ deeper into the soil. The excavation was finally refilled with sand compacted by trampling it underfoot in order to prevent it from being too loose. 


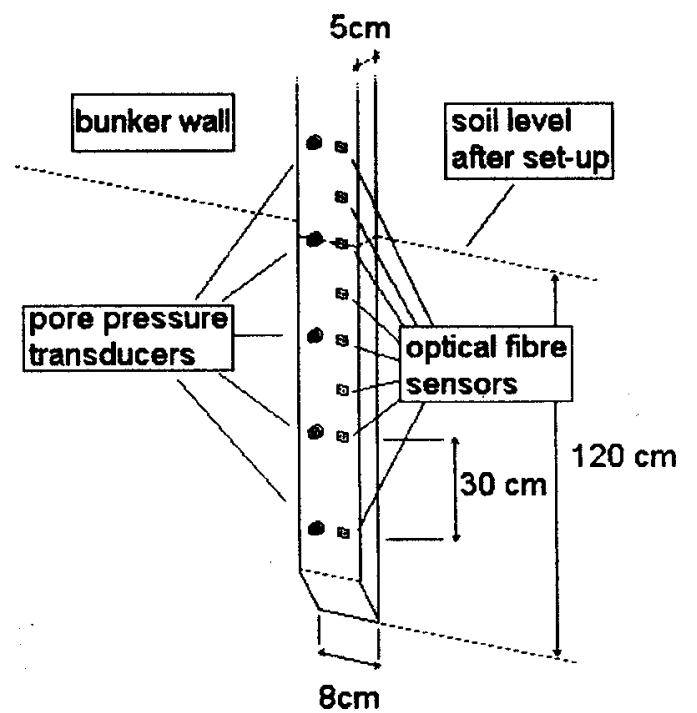

Fig. 5. Diagram of pressure sensors and fiber optics arrangement in the beam fixed on the bunker

\section{Measurements of Bed Level Variations}

Measurements of the bed surface position at the bar supporting the pressure sensors aimed at determining at any time which of the pressure sensors were inside the soil or in the water layer. Two original systems were designed for this purpose and tested in the framework of the study. The first one, a conductivity system, was tested as a prototype during the final field trial but it failed to predict the soil position. The problem was due to the use of direct current, which could have induced polarization problems. Since then, the design and successful testing of a new prototype using alternating current has been reported in Cassen and Abadie (2004). The second system was based on the optical backscattering of light by particles. Five fiber optics sensors were placed in the bar near to the pressure measurement positions (Fig. 5) and three additional fiber optics sensors were located in between the four upper pressure sensors. Each fiber optics sensor consists of two optical fibers set in parallel, the fiber tips facing outside the bar. One of the fibers is the light emitter and the other receives the backscattered light. The presence or absence of soil in front of the sensor is detected from the reflected light level. To remove surrounding light effects, the incoming light is switched alternately on and off (frequency $500 \mathrm{~Hz}$ ). The level of backscattered light when the emission is off is subtracted from the measurement when it is on. As sediment color and size vary in the field, any calibration to estimate sediment concentration is unrealistic. The discrepancy in the response between the light reflected by particles or bubbles has also not been perfectly determined yet. Anyway, the fiber optics system allows determining whether the sensor is in the soil or not, whether there is grain mobility in the soil, and whether there are changes in the water column [in Bonjean et al. (2004) the typical response of an optical sensor during a calibration test is shown].

Comparison was made between the fiber optics measurements and the bed position given by a graduated steel pole standing on the sand bed. The position of the pole indicates the level of the soil with the bearing capacity. The pole falls over when erosion or liquefaction occurs and it was possible to lift the pole by means of pulleys and ropes while recording data. As the wave conditions were fairly calm during the final field trial, video images of the soil position taken by a diver in the water layer near the pressure

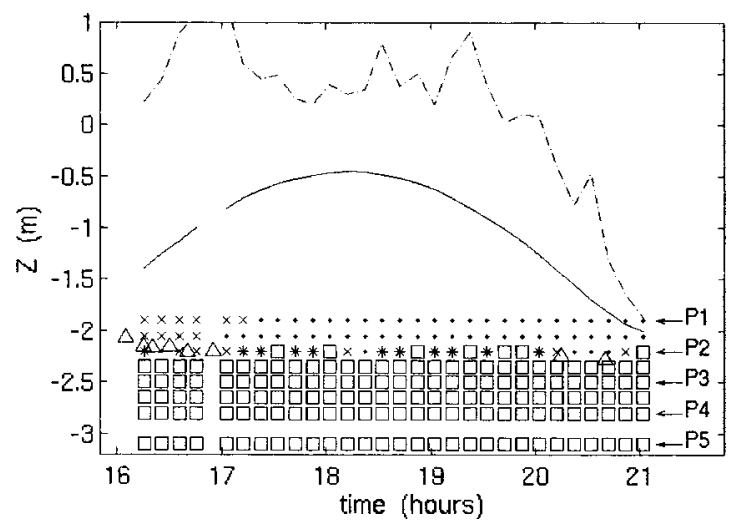

Fig. 6. Change in bed position during a tidal cycle (September 27, 2003). Arrows indicate the positions of the five pressure sensors. The bed level position indicated by the pole is given by triangles. The sediment environment detected by the eight fiber optics sensors during a $10 \mathrm{~min}$ period is indicated as follows: sensor inside soil (squares); sensor alternatively in soil or in water (asterisk); sediment or bubbles suspended in front of the sensor (crosses); fiber optics sensor in water (circle); mean water level (solid line); and maximum water level (dashed-dotted line).

beam could also be interpreted to determine the bed position when the suspension was sufficiently low. The observations of video images were occasionally compared with measurements.

The change in bed level position during a tidal cycle, measured at the beam supporting the pressure and fiber optics sensors, is presented in Fig. 6. Position $Z=0$ is the top of the bunker (the initial position of the bed at low tide was $13 \mathrm{~cm}$ below $P_{1}$, i.e., at $Z=-1.77 \mathrm{~m}$ ). In Fig. 6 the state of the eight fiber optics sensors is indicated by different symbols indicating whether the sensors are inside the soil, in air, or in water, or if suspended sediment or bubbles are passing in front of them. The data are given as averaged values over periods of $10 \mathrm{~min}$. It is also indicated when the sensor is alternatively in the soil or in water during the $10 \mathrm{~min}$ period. In the calm conditions of the day considered in Fig. 6, limited erosion was measured at the beam during a tidal cycle, and redeposition occurred at the end of the tidal cycle. Indications given by the fiber optics sensors and measurements of the pole position were in sufficiently good agreement to determine which of the pressure sensors were inside the soil, in the water layer or in suspended sediment, or at a position close to the bed level.

\section{Velocity and Pressure Measurements in the Water Layer}

Time series of velocity and pressure in the water layer were measured using a Nortek vector acoustic Doppler velocimeter (ADV). The ADV was fixed on the bunker in the vicinity of the bar supporting the pressure and fiber optics sensors. The data were sampled at rates ranging from 8 to $64 \mathrm{~Hz}$. Nortek recommends an average correlation of $70 \%$ for good quality data; but the mean of a velocity time series is valid for a correlation as low as $30 \%$ (Elgar et al. 2001). Most of our velocity data measured in the surf zone had a correlation coefficient of between 40 and $70 \%$ and only a limited quantity of data had correlation coefficients above $70 \%$. The presence of saltating particles and of air bubbles in the ADV sensing volume was found to be partly responsible for the increase in noise levels and the drop in correlation. All data were visually inspected for dropouts or outliers using Matlab (The 


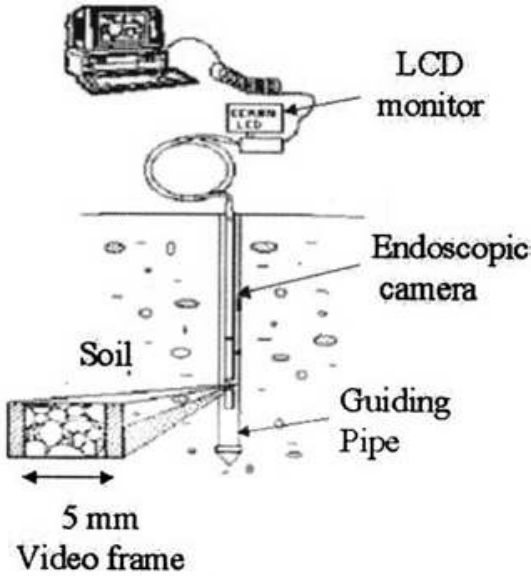

Fig. 7. Diagram of the endoscopic device

MathWork, Inc., Natick, Mass.). A technique to correct an outlier was employed following Goring and Nikora (2002) and Wahl (2003). The measured time variations of the water level and of the three velocity components were interpreted to estimate the mean flow components, wave properties, and turbulence level close to the bar.

\section{Gas Content Measurements inside the Soil}

A direct investigation of gas content in the soil was carried out using a geoendoscopic technique. Geoendoscopy has been developed and used for several years (Breul 1999) in order to provide in situ geotechnical characterization of soil. This technique uses a $8.6 \mathrm{~mm}$ diameter videoendoscope. Fig. 7 displays a diagram of the video endoscope. A 14-mm-diameter plexiglass tube was fixed on the bunker and extended inside the soil. The videoendoscope could be freely displaced inside the tube to monitor the soil at different depths. Analysis processing of the video images in the soil is then used to determine different soil parameters (particle size analysis, void, shape of particles, contact orientation, etc.). Eight tests were carried out by placing the plexiglass endoscopy tube at different locations around the bunker. Soil depths ranging from 0 to $1.10 \mathrm{~m}$ below the soil surface were investigated. Geoendoscopy was only available during the final field experiment trial (Fall 2003). It was used to observe the presence of gas inside the soil during a tidal period, to evaluate the gas content at different depths and to estimate the thickness of the mobile layer on top of the soil.

Gas content measurement techniques were the subject of a separate work package in the LIMAS project. A soil sampler for measuring gas content was designed in the course of the project. For operational reasons the gas sampler could not be tested during the final trial in September 2003, but separate experiments using the gas sampler were carried out in March 2004 (see Sandven and Long 2004).

\section{Conditions of the Field Experiment and Method of Operation}

The first three trials served to establish a general procedure of investigation and to test the instruments. A complete set of data was only obtained during the fourth and final field trial conducted from September 23 to 30, 2003. Although the wave conditions

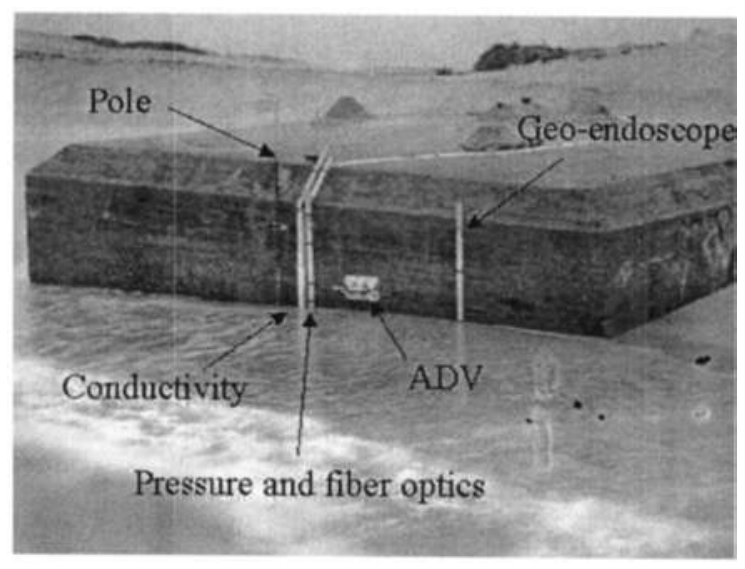

Fig. 8. Deployment of measurement systems approximately in the middle of the bunker wall facing the ocean

remained calm, significant phenomena regarding liquefaction could be observed. Most results presented in this paper were obtained during this trial. Several observations made during two earlier experiments, in October 2002 and April 2003, with much more active wave conditions are also presented, although the results cannot be completely analyzed, especially because systems to determine the soil position were not available.

Two configurations were investigated during the final field trial. The first one was set up on Tuesday, September 23, and left in place without disturbing the soil until Saturday, September 27. The beam supporting the pressure sensors and the associated instruments (conductivity tube, ADV, conductivity tube, pole) were fixed on the bunker approximately in the middle of the wall facing the ocean. Recordings were made during eight successive tidal periods, the last four of them corresponding to high tide conditions. At the same location the beam was lowered $39 \mathrm{~cm}$ on Saturday, September 27, and left for two more tides. In the second configuration, the instruments were all fixed close to the corner of the bunker. It was set up on Sunday, September 28, and left without disturbing the soil until Thursday, October 2, 2003. Recordings were made during seven successive tide periods, but only the first four periods had any significant tidal amplitude. Fig. 8 shows a photograph of the instruments deployed in the first configuration. The positions of the different devices described in the section entitled "Measurement Techniques for Observing Scour and Liquefaction" are identified.

The pressure variations measured by the five pressure sensors and the signals measured by the eight fiber optics sensors installed in the pressure beam were continuously recorded during each tidal cycle. The signals were transmitted to a PC acquisition system through a cable $100 \mathrm{~m}$ long and simultaneously recorded. The digitization frequency was $100 \mathrm{~Hz}$. Continuous records were also taken during the tidal cycles by the ADV, and the data were restored at the end of each tidal cycle. Because the clock of the ADV was synchronized with the clock of the acquisition PC, the data in the different time series can be interpreted at any time. The complete set of data consists of time series of pressure measurements inside the soil, of fiber optics measurements, and of pressure and velocity measurements in the water layer, acquired during each tidal cycle. A complementary measurement is the manual recording of displacements of the graduated pole. Photographs and video records taken from the beach, from the top of the bunker and inside the water layer were also taken. Finally, dynamic penetrometer measurements and DGPS measurements of 


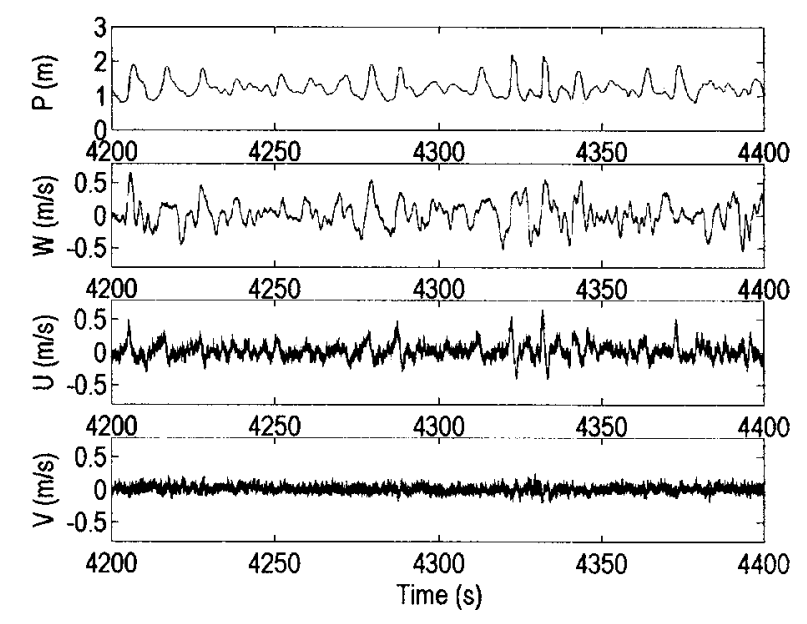

Fig. 9. Time series of velocities and pressure measured by the ADV (September 27, 2003) in the water layer

the soil level variations in the vicinity of the bunker were made in a systematic way at each low tide.

\section{Observation of Liquefaction Events}

\section{Pressure and Velocity Measurements in the Water Layer}

Fig. 9 shows a $200 \mathrm{~s}$ record of pressure and of the three velocity components measured by the ADV system. The $X$-direction ( $u$ velocity component) is the horizontal direction parallel to the bunker wall, the $Y$-direction ( $v$ velocity component) is the horizontal direction perpendicular to the wall, and the Z-direction ( $w$ velocity component) is the vertical direction parallel to the wall. Data spikes have been removed using the technique described in the section entitled "Velocity and Pressure Measurements in the Water Layer". The location of the ADV measurements was at a distance of $0.1 \mathrm{~m}$ from the bunker wall and $0.29 \mathrm{~m}$ from the bed. The most significant velocity component measured is the vertical one. The velocity component normal to the wall is almost zero. The horizontal velocity component parallel to the bunker wall can reach values as high as $0.4 \mathrm{~m} / \mathrm{s}$, but its magnitude is usually smaller than the vertical. The mean horizontal velocity components for the record in Fig. 9 were 0.011 and $-0.0013 \mathrm{~m} / \mathrm{s}$ for the directions parallel and perpendicular to the wall, respectively, indicating that waves arrive almost perpendicularly to the shore and the bunker. The wave height, deduced from the pressure record, is $H_{m 0}=0.99 \mathrm{~m}$ and the mean water depth is $1.53 \mathrm{~m}$. Although the wave activity was considered as being calm during the day, significant wave motions in the water layer occurred. Fig. 9 shows that the vertical velocity component is well correlated with the pressure and the periodicity of the signal is evaluated.

The power density spectra of pressure variations and of variations in the vertical velocity component are superimposed in Fig. 10(a). In the log-log scale of the plot the different frequencies of the wave motions are less visible as compared with what would appear in a linear-linear plot. On the other hand, it appears very clearly that pressure and velocity vary in a similar way in the low wave frequency range (frequencies less than $1 \mathrm{~Hz}$ ), whereas the two plots differ in the $1-10 \mathrm{~Hz}$ frequency range. The power spectrum of pressure variations decreases very rapidly in this frequency range, whereas a decay in $f^{-5 / 3}$ is observed over a decade for the power spectrum of the vertical velocity component. This $f^{-5 / 3}$ decay cannot be simply interpreted in terms of Kolmogorov theory because it is not found on the spectra obtained for the two horizontal velocity components [Fig. 10(b)]. However, it is remarkable that the pressure power spectrum and the vertical velocity power density spectrum overlap very well for frequencies less that $1 \mathrm{~Hz}$, whereas the vertical velocity power density spectrum is no longer related to pressure power density variations at higher frequencies. This indicates that the frequency of $1 \mathrm{~Hz}$ separates wave motions for frequencies below $1 \mathrm{~Hz}$ and turbulent motions for frequencies higher that $1 \mathrm{~Hz}$. The noise in the velocity measurements, observed for frequencies above $10 \mathrm{~Hz}$, is much greater for the horizontal velocity components than for the vertical velocity component. Several methods have been proposed to separate turbulent motions from mean flow and other organized motions of unsteady flows. We employed a direct filtration technique proposed by Longo et al. (2002) to estimate the energy contained in turbulent motions. This method misses the low frequency turbulence associated with large-scale eddies present under a bore, but the frequency range to consider for applying the filtration can be easily determined from Fig. 10(a). The RMS turbulent velocity of turbulent motions in the $1<f<20 \mathrm{~Hz}$ frequency band was found to be $0.025,0.024$, and $0.010 \mathrm{~m} / \mathrm{s}$ for the $u, v$, and $w$ velocity components, respectively. These estimates were made by integrating the different energy spectra in the $1<f<20 \mathrm{~Hz}$ frequency band, from which the noise level was subtracted. Although the results show a departure from isotropic turbulence, which cannot

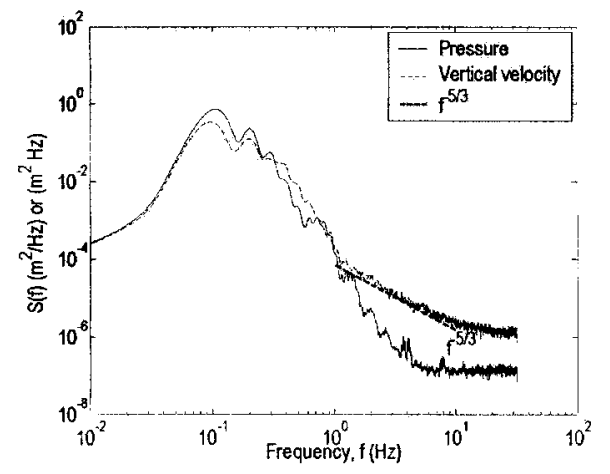

(a)

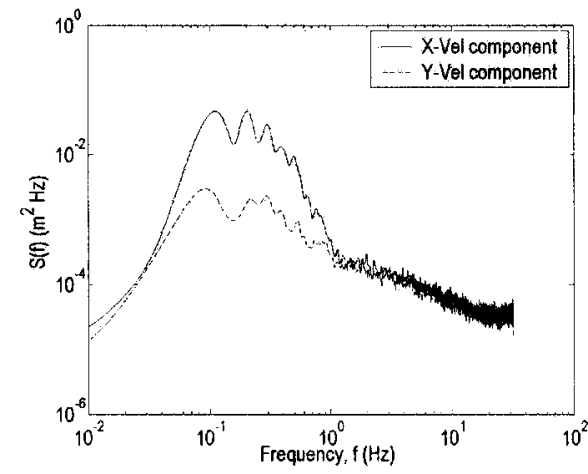

(b)

Fig. 10. (a) Pressure and vertical velocity spectra; (b) spectra of the horizontal velocity components (September 27, 2003) 

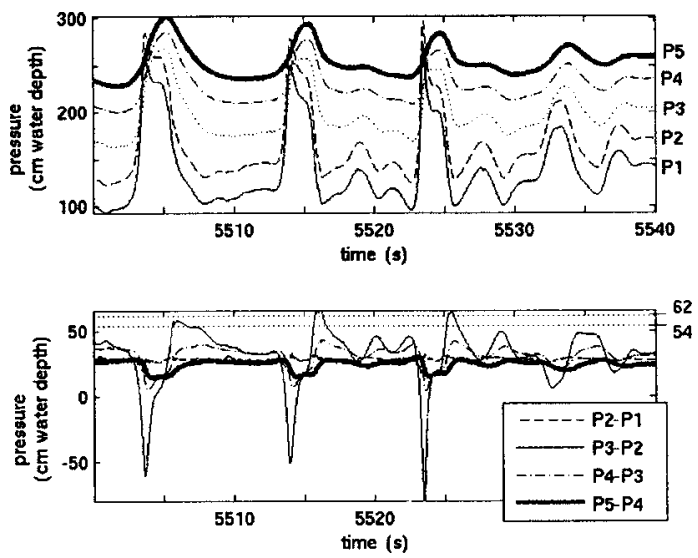

Fig. 11. Water pressure recorded by Pressure Sensors $P_{1}-P_{5}$ in high tide conditions (September 27, 2003, 18:27)

be simply interpreted because the main component is the vertical one, we retain that the turbulence level is relatively small. The most significant result of the velocity and pressure measurements in the water layer is that motions are primarily surface wave motions with limited mean and turbulent motions superimposed for the low wave activity conditions of September 27, 2003.

\section{Observations of Liquefaction Occurrence from Pore Pressure Measurements}

Fig. 11(a) presents a time series of the absolute pore pressure measured simultaneously by the five pressure sensors. The significant wave height at the bunker for this record was about $1.10 \mathrm{~m}$ and the water depth $2.0 \mathrm{~m}$. The spectral peak frequency was about $0.11 \mathrm{~Hz}\left(T_{p}=8.82 \mathrm{~s}\right)$. The maximum pressure level is recorded by the lowest pressure sensor $\left(P_{5}\right)$, whereas the minimum pressure level is recorded by the highest pressure sensor, $P_{1}$. The time series covers only a period of $40 \mathrm{~s}$ (i.e., about four wave periods) allowing a detailed analysis of pore pressure variations inside the soil. The three lowest sensors, $P_{3}, P_{4}$, and $P_{5}$, were inside the soil. Fig. 11(a) displays clear damping of pressure variations with increasing distance inside the soil (from $P_{2}$ to $P_{5}$ ). A phase shift is also noticeable. At each depth the maximum pressure is reached later than the time when the maximum pressure is measured by Sensors $P_{1}$ or $P_{2}$. The phase shift increases with increasing distance from the bed surface. The pressures are converted into water depth and the averaged pressure difference between two neighboring sensors is about $0.3 \mathrm{~m}$, which is the distance between two sensors. Similar phenomena are observed during the first three wave periods shown in Fig. 11(a). A sudden and very rapid increase in the pressure measured by Sensors $P_{1}$ and $P_{2}$ is observed first. The maximum pressure is measured when the wave crest is on the bunker. $P_{1}$ is in the water layer and $P_{2}$ is very close to the bed surface (either in the water layer or inside the soil), and therefore the pressure variations measured by the two sensors are almost the same, as shown by the pressure difference $P_{2}-P_{1}$ plotted in Fig. 11(b). The pressure increases subsequently inside the soil with a certain delay. Although the pressure inside the soil is still increasing, there is a strong decrease in pressure at $P_{1}$ and $P_{2}$, which corresponds to the wave through in the water layer. At times $t=5,506,5,516$, and $5,526 \mathrm{~s}$ the pressure difference $P_{3}-P_{2}$ are about $0.58,0.65$, and $0.65 \mathrm{~m}$, respectively [Fig. 11(b)]. When the pressure difference exceeds a certain positive value, it can overcome the effective weight of the

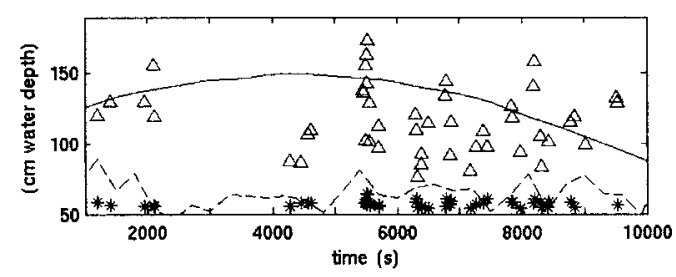

(a)

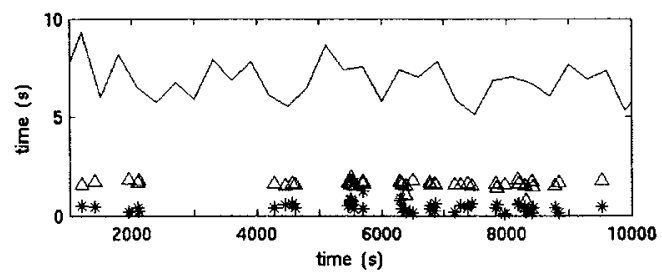

(b)

Fig. 12. Occurrence of liquefaction during a tidal cycle (September 27, 2003). (a) Maximum pressure $\Delta P_{3.2}$ (asterisk); height of the wave crest preceding the liquefaction event (triangle); mean water depth (solid line), and; significant wave height (dashed line). (b) Duration of liquefaction event (asterisk); delay between the preceding wave crest and the start of the event (triangle); and wave period (solid line).

sediment layer, which is no longer in static equilibrium. The critical pressure difference $\Delta P_{3.2}=P_{3}-P_{2}$ required to overcome the effective weight of the soil is

$$
\Delta P_{3.2}=\rho_{f} g h\left\{\frac{\rho_{s}}{\rho_{f}}(1-\varepsilon)+\varepsilon-\varepsilon C_{\mathrm{gas}}\left(1-\frac{\rho_{g}}{\rho_{f}}\right)\right\}
$$

$\rho_{s}, \rho_{f}$, and $\rho_{g}=$ densities of sediment, water, and gas, respectively; $h=$ distance between the two sensors; $\varepsilon=$ porosity of the soil; and $C_{\text {gas }}=$ the gas content. The value of the critical pressure difference $\Delta P_{3.2}$ depends mainly on the density of particles and on the soil porosity. We estimate that the critical upward pressure difference (converted into water depth) for breaking the static equilibrium of the sediment layer contained between two sensors ranges between 0.54 and $0.62 \mathrm{~m}$ (the distance between two neighboring sensors is $30 \mathrm{~cm}$ ). The lower estimate is obtained for a density of particles $\rho_{s}=2,600 \mathrm{~g} / \mathrm{L}$ and a porosity $\varepsilon=0.5$, whereas the higher estimate corresponds to $\rho_{s}=2,750 \mathrm{~g} / \mathrm{L}$ and $\varepsilon=0.4$. The main dependence is on the soil porosity, which is quite unknown. On the one hand, soil porosity $\varepsilon=0.4$ corresponds to compact soil, as found at the beginning of each experiment. On the other hand, when the soil has been significantly redrafted due to scour, liquefaction, and fresh sand deposits, we may find soil porosity as high as 0.5. For the estimates given previously, the degree of saturation has not been taken into account. Eq. (1) shows that the presence of gas reduces the critical pressure difference by about $0.01 \mathrm{~m}$ for a gas content $C_{\mathrm{gas}}=6 \%$ (see the section entitled "Analysis of Pore Pressure Measurements inside the Soil" for a discussion of this value). The phenomenon observed in Fig. 11 for the three periods considered is interpreted as events of momentary liquefaction occurrence. The sensitivity range $0.54-0.62 \mathrm{~m}$ for liquefaction occurrence is indicated in Fig. 11(b) by the two horizontal dotted lines showing the two levels. The three events shown in Fig. 11 are clearly independent. They just look similar because the wave conditions are almost the same for the successive periods, but the typical evolutions occur within each period. The comparison of superposed Figs. 11(a and b) shows clearly that liquefaction occurs at the moment when the wave through is passing in the water layer. 


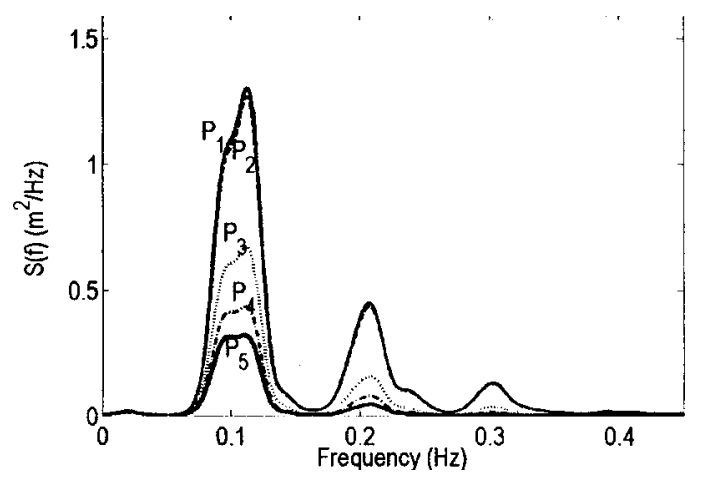

Fig. 13. Energy density spectra of pore water pressure measurements at five different levels. The distance between two successive sensors is $30 \mathrm{~cm}$ in the vertical direction.

A statistical analysis of the occurrence of liquefaction events is carried out in the next section and the following section analyzes the pressure measurements in greater detail using a Fourier analysis. However some properties of liquefaction events can be mentioned already because they are visible in Fig. 11. First, it is observed that the pressure difference between two sensors does not usually exceed the critical value by very much. When liquefaction occurs, the sediment layer is dilated, the porosity in the soil increases, and the pore pressure is rapidly adjusted to the value on top of the soil. Liquefaction events are of short duration.

\section{Statistical Analysis of Liquefaction Events during a Tidal Period}

The occurrence of liquefaction events and the conditions in which they were observed were analyzed in a systematic way. In Fig. 12(a) the times of occurrence of liquefaction events are represented during $2.5 \mathrm{~h}$ of a tidal cycle. The maximum pressure difference $\Delta P_{3.2}$ between Pressure Sensor $P_{2}$ (around the bed surface) and Pressure Sensor $P_{3}\left(30 \mathrm{~cm}\right.$ below $\left.P_{2}\right)$, the mean water depth, the significant wave height, and the wave height in the water layer of the wave preceding the liquefaction event are plotted in the same diagram for each event. The critical value of $\Delta P_{3.2}$ required for liquefaction to occur was stated to be $0.54 \mathrm{~m}$, as computed in a previous section. In Fig. 12(b) the duration of liquefaction events, the delay between the preceding wave crest and the start of liquefaction, and the wave period are given for each liquefaction event. During the $2.5 \mathrm{~h}$ considered, 47 liquefaction events were observed. The maximum pressure difference $\Delta P_{3.2}$ is usually less than $0.60 \mathrm{~m}$, presumably because liquefaction produces a dilated suspension in which the pore pressure rapidly decreases, and the duration of the liquefaction events is less than $1 \mathrm{~s}$. Because the measured pressure difference $\Delta P_{3.2}$ is not significantly higher than the critical value of $0.54 \mathrm{~m}$, the effective occurrence of liquefaction may appear questionable. It should however be pointed out that this pressure difference is measured between two sensors located at a distance of $30 \mathrm{~cm}$ along a vertical in the soil. This is a significant depth for a liquefied layer. It may be expected that more numerous liquefaction events involving a sediment layer less than $0.3 \mathrm{~m}$ thick did occur but were not detected.

\section{Analysis of Pore Pressure Measurements inside the Soil}

On the basis of spectral frequency analysis of pore pressure, it is possible to quantify the damping of pore pressure variations in-

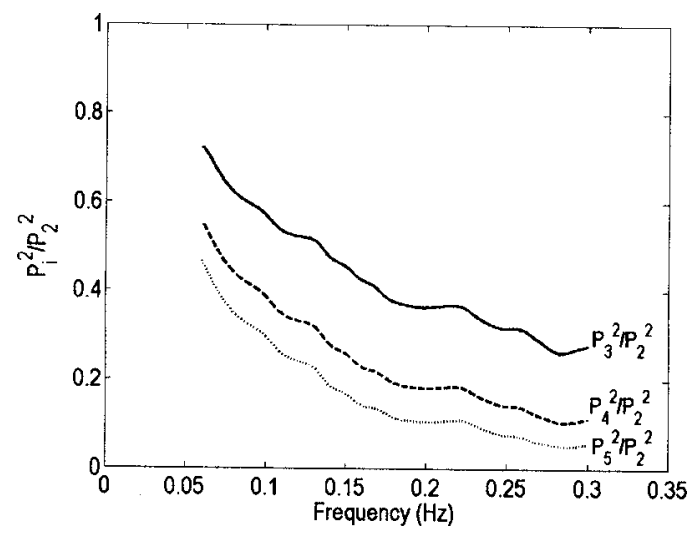

Fig. 14. Ratio of pressure variance inside the bed layer (Pressure Sensors $\left.P_{3}-P_{5}\right)$ to pressure variance in the water layer near the bed surface (Pressure Sensor $P_{2}$ )

side the soil. Fig. 13 shows the typical energy density spectra of the pore water pressure measured simultaneously by the five pressure sensors. Three simply related frequencies appear in the frequency spectrum. Because the phase information vanishes in the power spectrum, the decay of pressure variations with increasing distance inside the soil is easily determined by comparing the value of the power spectrum measured at different levels for each frequency. The power spectra measured by Pressure Sensors $P_{1}$ and $P_{2}$ are almost identical. This is an expected result because the two sensors are in the water layer and they are only separated by a distance of $30 \mathrm{~cm}$. The pressure decay inside the soil can be quantified as the ratio of the variance of the pressure spectral power density $P_{i}$ at a location $z_{i}$ below the seabed to the value at the bed surface determined from $P_{2}$. This is plotted in Fig. 14 as a function of frequency. A strong and continuous decay of pore pressure variations is found in the $0.9 \mathrm{~m}$ layer of bed considered. For all depths, the ratio of the pressure variance decreases nonlinearly with increasing frequency, i.e., damping increases with increasing frequency.

Sakai et al. (1992) published a set of equations that computes the wave-induced effective stress in the seabed. This model actually originates from Mei and Foda (1981). It describes the variation in time of pore pressure in the seabed when a monochromatic wave passes over an elastic plane sandy bed. This geometry is obviously different from ours. Although implementing the theory of Sakai et al. is inappropriate for describing in detail the process of liquefaction occurring in our experiments, our goals in comparing field experiment data with the theory of Sakai et al. are qualitative and also partly quantitative. We first compare qualitatively the mechanisms producing liquefaction, as quantified by the decay and phase shifts of pressure variations in the soil. The theory of Sakai et al. is derived for a monochromatic linear wave, but the spectral analysis allows comparing field data with the theory of Sakai et al. of the decay coefficient and of the phase lag for the different frequencies, in spite of obvious shortcomings. The analysis was performed in order to consider whether the decay rates and phase shifts in pressure variations measured in the field could be recovered from the solution of Sakai et al. for consistent soil parameter values. We can then deduce qualitative conclusions relative to the parameters triggering the process of liquefaction from the quantitative comparison of decay coefficients and phase shifts.

Pore pressure variation inside the bed is given by Eq. (3) of Sakai et al. (1992) 


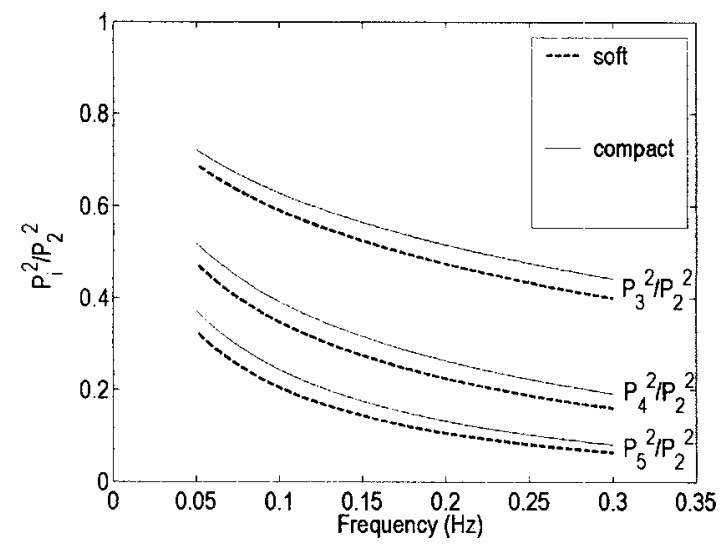

Fig. 15. Ratio of pressure variance inside the bed layer to pressure variance in the water layer near the bed surface predicted by the model by Sakai et al. (1992) for $C_{\mathrm{gas}}=0.01$. Soft soil conditions: $n=0.50, k=2.0 \times 10^{-4} \mathrm{~m} \mathrm{~s}^{-1}, G=2 \times 10^{7} \mathrm{~N} \mathrm{~m}^{-2}$, and $\nu=0.498$. Compact soil conditions: $n=0.40, k=2.0 \times 10^{-4} \mathrm{~m} \mathrm{~s}^{-1}, G=2 \times 10^{8} \mathrm{~N} \mathrm{~m}^{-2}$, and $\nu=0.33$.

$$
\frac{P(z)}{P_{0}}=\left[\frac{1}{1+m} e^{-\lambda z}+\frac{m}{1+m} e^{[(i-1) z] /(\sqrt{2} \delta)}\right] e^{i(\lambda x-\sigma t)}
$$

where $\lambda$ and $\sigma=$ wave number and frequency of the wave propagating in the water layer, respectively. The $z$ axis is oriented downward and $z=0$ is at the bed surface. The parameters appearing in Eq. (2) are defined as

$$
\begin{gathered}
m=\frac{n}{1-2 v} \frac{G}{\beta}, \quad \beta=\frac{1}{\beta_{w}}+\frac{C_{\mathrm{gas}}}{P_{\mathrm{ref}}}, \\
\delta=\left(\frac{k}{\rho g} \frac{G}{\sigma}\right)^{1 / 2}\left[\frac{n G}{\beta}+\frac{1-2 v}{2(1-v)}\right]^{-1 / 2}
\end{gathered}
$$

where $\beta=$ coefficient of compressibility of water and $P_{\text {ref }}=$ averaged level of pressure. An important issue of the model of Sakai et al. is the very significant sensitivity of the results to the gas content in the soil $C_{\text {gas }}$, as shown by Gratiot and Mory (2000). $C_{\text {gas }}$ is actually the "tuning coefficient" of the model, and the other soil parameters have a more limited effect on the results. Fig. 15 shows the variation in pressure variance computed by the equation of Sakai et al. at the position of Pressure Sensors $P_{3}-P_{5}$ as compared with the pressure variations measured at the bed surface $\left(P_{2}\right)$. Two computations are presented, for a soft soil condition and for a compact soil condition, as considered by Gratiot and Mory (2000) in their sensitivity analysis of the theory of Sakai et al. For the soft soil conditions, the bed porosity $n=0.50$, the bed permeability $k=2.0 \times 10^{-4} \mathrm{~m} \mathrm{~s}^{-1}$, the elasticity of the soil given by the shear modulus of the solid skeleton $G=2 \times 10^{7} \mathrm{~N} \mathrm{~m}^{-2}$ and the Poisson modulus $\nu=0.498$ have been chosen. For the compact soil conditions, we set $n=0.40$, $k=2.0 \times 10^{-4} \mathrm{~m} \mathrm{~s}^{-1}, G=2 \times 10^{8} \mathrm{~N} \mathrm{~m}^{-2}$, and $\nu=0.33$. The level of gas content was adjusted to $C_{\text {gas }}=0.01$ for the comparison shown in Fig. 15. Very significant variations of the plot shown in Fig. 15 would be obtained if $C_{\text {gas }}$ is varied, but we can see in Fig. 15 that the other soil parameters have a limited effect on the result for the gas content level $C_{\text {gas }}=0.01$ considered. The plot is made versus frequency and the results of Fig. 15 can therefore be compared directly to the field results in Fig. 14. Both the shapes of the curves and the quantitative values are comparable in Figs. 14 and 15 , which is a very striking result. We expect that the soft soil conditions should satisfactorily represent the soil conditions when

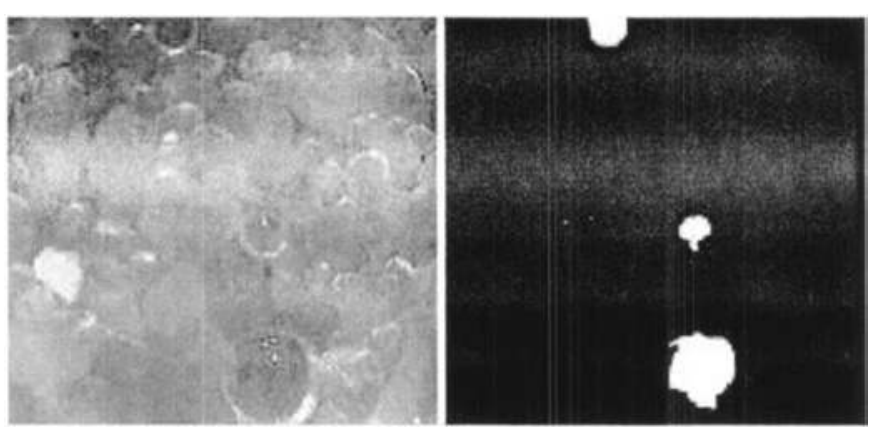

Fig. 16. Recorded image and processed image showing bubble extraction

repeated liquefaction events and depositions occur, as observed in Fig. 11(a), but the soil conditions at the beginning of each tide are presumably better given by the compact soil conditions. Although the cases investigated in the field and the configuration considered by Sakai et al. (1992) are different, the comparison of Figs. 14 and 15 is reasonably good. As the gas content is the tuning coefficient, measuring significant damping of pressure in the soil, as shown in Fig. 14, indicates, according to the model calculations, that the gas content in the soil is high. This is a strong indication that the presence of gas inside the soil has to be considered.

The phase lags between the pore pressure variations measured at different depths inside the bed and pressure variations measured at the bed surface by Sensor $P_{2}$ have also been compared for the different frequencies to the computations from the model of Sakai et al. Similar values of the phase shift are obtained and similar decays of the phase shift with increasing frequency are observed. This is not shown here because of the limited space available, although this supports again the significance of this comparison.

\section{Gas Content Measurements inside the Soil}

Images of a $25 \mathrm{~mm}^{2}$ area with a magnification of 10 were acquired using the videoendoscope. Fig. 16 shows a typical image captured by the videoendoscope. Sediment particles and bubbles are easily distinguished. The recorded images were subjected to signal processing, which is not described in this paper, in order to analyze the soil automatically and extract information on the soil parameters (size of gas bubbles and particles, contact orientations, etc.). Fig. 16 shows the processed image in which bubbles have been extracted as black and white pictures. The "surface gas content ratio" was then computed as the ratio of the area filled with gas bubbles to the total area of the image.

The major result of the geoendoscopic measurements is the evidence they provided of significant quantities of gas deep inside the soil, down to $0.50 \mathrm{~m}$ in the case investigated. A thin sediment layer of about $0.10 \mathrm{~m}$ saturated with water is observed on top of the soil. Below this, a sediment layer containing a significant amount of gas is observed, and gas is again seen to vanish deeper inside the bed. The thickness of the saturated layer on top of the soil is linked to the mobility of the sand produced by waves which enhance the upward escape of bubbles, whereas the thickness of the gas-containing layer roughly corresponds to the layer of sand drained at low tide. Values of the "surface" gas content as high as $6 \%$ are found inside the soil.

Interpreting the "surface gas content" in terms of the bulk gas content is not a straightforward matter. Assuming that $N_{V}$ spherical bubbles of diameter $D$ are contained in a unit volume, the bulk 
gas content is $C_{v}=N_{v} \pi D^{3} / 6$. Considering now all bubbles which are visible in a frame of size $L^{2}$ and depth of focus $e$, it is quite easy to show that the surface of bubbles seen on the image is $N_{v} \pi D^{2} L^{2}(e / 4+D / 3)$. The surface gas content is thus $C_{s}=N_{v} \pi D^{2}(e / 4+D / 3)$. Comparing the expressions for $C_{v}$ and $C_{s}$, we deduce

$$
C_{v}=\frac{C_{s}}{2+(3 e / 2 D)}
$$

Eq. (4) exhibits interesting properties. When the depth of focus is small compared to the bubbles diameter, $C_{v}=C_{s} / 2$ and Eq. (4) no longer depends on the bubbles diameter. Eq. (4) should be used with care, as it is a statistical estimate for a large number of bubbles distributed homogeneously in the medium. For its application to endoscopic measurements, it also ignores that air bubbles observed tend to stick and flatten against the plexiglass wall of the geoendoscopic tube. The interesting conclusion of Eq. (4) is however that measuring surface gas content and bulk gas content is essentially the same, and similar values are obtained from the two estimates.

Measurements of gas content using the geoendoscopic system thus clearly demonstrate the existence of significant gas content inside the soil. This is one important conclusion from our field experiment, but it should be handled with care and not be stated as a general conclusion, as discussed later, because the sea was fairly calm in the course of the final field trial during which videoendoscopy was employed. The observations described earlier may not be made in rougher wave conditions. The presence of gas inside the soil is clearly caused by the tidal variations. Gas is introduced inside the soil at low tide when the water level is below the soil level, and full saturation of the soil with water is not simply recovered when the tide goes up. Some air bubbles are trapped inside the soil, and some of our video measurements inside the soil clearly show that the mobility of soil grains helps gas bubbles to escape from the soil.

\section{Conclusions}

The field experiments carried out at Capbreton aimed primarily at observing the occurrence of liquefaction in the vicinity of a coastal structure subjected to wave forcing. To our knowledge, the phenomenon has not been observed before in the field. From pore pressure measurements inside the soil, it was observed in a number of cases during our experiments that a sediment layer does not remain in static equilibrium. The phenomenon is interpreted as momentary liquefaction, because no buildup of pore pressure is observed and the phenomenon is seen to dissipate within the wave period during which it occurs. The phenomenon is also found to be significant because pressure sensors were installed at levels separated by a distance of $30 \mathrm{~cm}$. Momentary liquefaction events were only detected when the depth of the liquefied sediment layer exceeded $30 \mathrm{~cm}$. It may be expected that more numerous liquefaction phenomena occurred, involving thinner liquefied sediment layers.

The results obtained in the course of the study have only been partly presented in this paper, which aims at providing a general account of the field experiments, their conditions, the experimental setup employed and the general conclusions. Due to limited space, the emphasis was placed on a chosen tidal cycle to describe the occurrence of liquefaction.

The pore pressure measurement installation made it possible to quantify the damping of pore pressure variations and the phase shift in pressure variations measured at different levels inside the soil. Using a Fourier analysis of pressure variations measured at different levels, a reasonable agreement was obtained between the damping and phase shifts measured in the field and the results of the model of Sakai et al., although the configurations are quite different. This comparison provided an estimate of gas content inside the soil. The model indicated a significant amount of gas inside the soil, with the order of magnitude of $1 \%$. The presence of gas was confirmed by geoendoscopic videos inside the soil. Bubbles were observed inside the soil and orders of magnitude of a few percent were confirmed. The geoendoscopic equipment was only available for two days of our experiments, but this was sufficient first to find evidence of gas content, and second to demonstrate the promising features of geoendoscopy for this subject.

Complete sets of data were only obtained during the final field trial, but unfortunately wave activity was calm during this period (with wave heights of $1 \mathrm{~m}$ at most). The conditions were however sufficient to demonstrate the occurrence of liquefaction. Much greater wave activity was experienced during the preceding field trials in October 2002 and April 2003, but the erosion and deposition were also much more significant during these trials. They will be addressed in a subsequent paper that will contain a more detailed analysis of the pressure sensors in different wave conditions and at different locations around the bunker. The presence of gas inside the soil in rougher wave conditions will be discussed more extensively in relation to the measurements made by Sandven and Long (2004) at Capbreton.

\section{Acknowledgments}

This study was partially funded by the European Commission Research Directorate, FP5, specific program "Energy, Environment, and Sustainable Development," Contract No EVK3-CT2000-00038, Liquefaction around Marine Structures LIMAS (http://www.isva.dtu.dk/limas:public/limas2.html). The writers thank J. P. Barbier for the design and construction of the fiber optics system. C. Carrère and J. P. Dufau are also acknowledged for having made possible the experimentation at Capbreton.

\section{References}

Bonjean, D., Foray, P., Piedra-Cueva, I., Michallet, H., Breul, P., Haddani, Y., Mory, M., and Abadie, S. (2004). "Monitoring of the foundations of a coastal structure submitted to breaking waves: Occurrence of momentary liquefaction." Proc., 12th ISOPE Conf., Toulon, France.

Breul, P. (1999). "Caractérisation endoscopique des milieux granulaires couplée à l'essai de pénétration." Thèse de docteur- ingénieur, Université de Clermont-Ferrand, 280 pages (in French).

Cassen, M., and Abadie, S. (2004). "On the use of electrical resistivity measurements to monitor local depth evolution in the surf zone." 29th ICCE Conf., Lisbon, Portugal.

Elgar, S., Raubenheimer, R., and Guza, R. T. (2001). "Current meter performance in the surf zone." J. Atmos. Ocean. Technol., 18, $1735-1746$

Goring, D. G., and Nikora, V. I. (2002). "Despiking acoustic Doppler velocimeter data." J. Hydraul. Eng., 128(1), 117-126.

Gratiot, N., and Mory, M. (2000). "Wave induced sea bed liquefaction with application to mine burial." Proc., 10th ISOPE Conf., Seattle.

Howa, H., Salomon, J. N., and Tastet, J. P. (1999). "Littoral aquitain." Acquis Sciences No. 20. 
Longo, S., Petti, M., and Losada, I. J. (2002). "Turbulence in the swash and surf zones: A review." Coastal Eng., 45, 129-147.

Mei, C. C., and Foda, M. A. (1981). "Wave induced responses in a fluidfilled poroelastic solid with a free surface-A boundary layer theory." Geophys. J. R. Astron. Soc., 66, 597-631.

Sakai, T., Hatanaka, K., and Mase, H. (1992). "Wave-induced effective stress in seabed and its momentary liquefaction." J. Waterway, Port,
Coastal, Ocean Eng., 118(2), 202-206.

Sandven, R., and Long, M. (2004). "Development of sampler for measurement of gas content." Submitted for publication in the J. Waterways, Port, Coastal and Ocean Engineering.

Wahl, T. L. (2003). "Discussion of 'Despiking acoustic Doppler velocimeter data' by Derek G. Goring and Vladimir I. Nikora.' "J. Hydraul. Eng., 129(6), 484-487. 